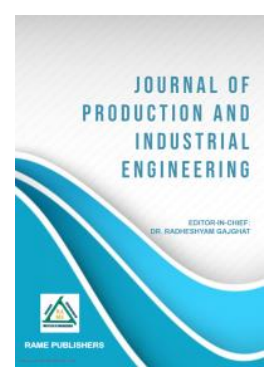

Sanju Manna sanjumanna2298@gmail.com

Raj Kumar Sen rajkumarshrivash374@gmail.com

Vikas Sharma vikassharma78557855@gmail.com

Shubham Sao shubhamsao4560.sss@gmail.com

Junaid Alam mdjunaid1224@gmail.com

Dr. P. S. Rao

srinivas.indore@gmail.com

Department of Mechanical Engineering, Christian College of Engineering \& Technology, Bhilai, India

\title{
Design and Development of Air Pollution Control Device to Remove NOx
}

Abstract - Air pollution causes a variety of respiratory ailments, including "asthma, lung cancer, chest pain, congestion, throat inflammation, cardiovascular disorders, and respiratory diseases". This contaminated environment not only harms human health, but it also harms plant development, reduces soil fertility, and alters soil structure. The primary contributors to this pollution are dust particles of various sizes, NOx gases that may contain microscopic particulates or liquid droplets small enough to enter the lungs and cause serious health concerns. Large particles have the potential to irritate the nose, throat, and eyes. Pneumoconiosis refers to a category of lung disorders caused by breathing in insoluble dusts, primarily mineral dusts, that the lungs cannot eliminate. With any dust particles that escaped the defenses in the nose and airways, the air reaches the tiny air suckers (alveoli) in the inner region of the lungs. So, in order to eliminate this effect, a little effort has been made to reduce the harmful effects of pollution and enhance human life by humanizing the state of the environment. The originality of the concept is that a single device will regulate the complete effect of pollution by separating dust as well as NOx emissions, which are extremely damaging to humans. This device will collect dust and other polluting gases from the environment and separate them. Finally, it will lessen the damaging effect of NOx gases by chemical reaction, leaving clear, clean gases in the air. An air pollution control device can be deployed anywhere to maintain pollution standards and improve human life.

Keywords- Respiratory problems, Human health, Growth of plants, Soil fertility, Dust particles, Chemical reaction.

\section{INTRODUCTION}

Energy consumption has risen dramatically in recent decades as a result of industrialization and accompanying

Technical Article - Peer Reviewed

Published online - 31 December 2021

(C) 2021 RAME Publishers

This is an open access article under the CC BY 4.0 International License https://creativecommons.org/licenses/by/4.0/

Cite this article - Sanju Manna, Raj Kumar Sen, Vikas Sharma, Shubham Sao, Junaid Alam, Dr. P. S. Rao, "Design and Development of Air Pollution Control Device to Remove NOx", Journal of Production and Industrial Engineering, RAME Publishers, vol. 2, issue 2, pp. 43-60, 2021.

https://doi.org/10.26706/jpie.2.2.20211204 lifestyle changes. The majority of this energy comes from fossil fuels including coal, natural gas, gasoline, and diesel. Almost $90 \%$ of current energy is derived from the combustion of fossil fuels and biomass. Pollutant emissions from combustion sources have become increasingly harmful to the environment in recent decades.

The project's goal is to test and improve air quality. Poor air quality has a negative impact on the health of millions of people. Clean air is a critical element for our daily lives. A variety of harmful pollutants, such as smog and deadly NOx emissions, are extremely hazardous to 
both human and animal life. This can lead to asthma, lung illness, and a variety of other lethal ailments throughout India and beyond. To safeguard our everyday lives from the harmful effects of pollution and to improve the quality of atmospheric air, a smart pollution control device should be deployed everywhere in order to maintain pollution norms and to improve human life.

This device will collect dust and other polluting gases from the environment and separate them. Finally, it will lessen the damaging effect of NOx gases by chemical reaction, leaving clear, clean gases in the air. The pollution control device is intended to reduce NOx and other pollutants. The gadget is currently being developed to minimise NOx pollution. In this case, an inline duct vent blower fan powered by electricity is used, and chemicals are used in the filter to transform polluted gases into safe, clean air.

Initially, a suction fan will pull dust-polluted air from the environment at any point along the road or near an industrial area. The sucked polluting gas will be sent via the separator / intern filter, separating the air from the dangerous NOx gases. While passing through the separator, the filter will be chemically wetted, and the chemical reaction will convert NOx gases into nonpolluting gases. Clean gas will flow through the lower area of the apparatus, while liquid mixed dust will fall into the bottom section of the filter section. The outlet flow pressure will force the flow into the atmosphere, and clean air will exit the chamber through the bottom exhaust port.

\section{a. Control of NOx}

NOx is a group of seven chemicals. Actually, the EPA only controls nitrogen dioxide $\left(\mathrm{NO}_{2}\right)$ as a proxy for this family of chemicals because it is one of the most abundant forms of NOx in the atmosphere caused by anthropogenic (human) activity. Not only is $\mathrm{NO}_{2}$ a significant air pollutant in and of itself, but it also reacts in the atmosphere to generate ozone $\left(\mathrm{O}_{3}\right)$ and acid rain. It is vital to remember that the ozone we wish to reduce is tropospheric ozone, which is ozone in the air we breathe.
We're not talking about the high atmosphere's stratospheric ozone, which we can't breathe. Stratospheric ozone shields humans and the troposphere from the sun's ionizing radiation. In the existence of air and ultraviolet light (UV) from sunlight, $\mathrm{NO}_{2}$ interacts to generate ozone and nitric oxide (NO). The NO then combines with free radicals in the environment, which are also produced when UV rays interact with volatile organic molecules (VOC). $\mathrm{NO}$ is then recycled to $\mathrm{NO}_{2}$ by the free radicals. As a result, each NO molecule can create ozone many times. This will continue until the VOCs are reduced to short carbon chains that are no longer photo reactive (a reaction caused by light). A VOC molecule may typically accomplish this 5 times.

Aside from the worries about NO2 and Ozone National Ambient Air Quality Standards (NAAQS), NOx and sulphur oxides (SOx) in the atmosphere are collected by moisture to generate acid rain. Acid rain, together with cloud and dry deposition, has a negative impact on particular ecosystems and has a direct impact on various sectors of our economy. All of these facts point to a clear need to minimize NOx emissions. To do so, however, we must first understand the NOx family of air pollutants and how to reduce them [1].

\section{b. Nitrogen oxide}

Diatomic molecular nitrogen $\left(\mathrm{N}_{2}\right)$ is a relatively inert gas that accounts for roughly $80 \%$ of the air humans breathe. However, as a single atom, the chemical element nitrogen $(\mathrm{N})$ can be reactive and have ionization levels ranging from +1 to +5 . As a result, nitrogen can produce a variety of oxides. According to the Niels Bohr model of the atom, valence state is the number of electrons in the ion that are either deficiency (+ valence) or surplus (valence) when compared to the neutral molecule. Table 1 lists the NOx compound family and its attributes.

When any of these oxides dissolve in water and decompose, nitric acid $\left(\mathrm{HNO}_{3}\right)$ or nitrous acid is formed $\left(\mathrm{HNO}_{2}\right)$. When nitric acid is neutralized, it produces nitrate salts. Nitrite salts are formed when nitric acid reacts with oxygen. Thus, NOx and its derivatives present 
and react as gases in the air, acids in water droplets, or salts. These gases and salts all contribute to the pollution consequences observed and caused to acid rain.

TABLE 1

NiTROGEN OXIDES $\left(\mathrm{NO}_{\mathrm{X}}\right)$

\begin{tabular}{|c|c|c|c|}
\hline Formula & Name & $\begin{array}{c}\text { Nitrogen } \\
\text { Valence }\end{array}$ & Properties \\
\hline $\mathrm{N}_{2} \mathrm{O}$ & Nitrous oxide & 1 & $\begin{array}{c}\text { Colorless gas water } \\
\text { soluble }\end{array}$ \\
\hline $\begin{array}{c}\mathrm{NO} \\
\mathrm{N}_{2} \mathrm{O}_{2}\end{array}$ & $\begin{array}{c}\text { Nitric oxide } \\
\text { dinitrogen dioxide }\end{array}$ & 2 & $\begin{array}{c}\text { Colorless gas } \\
\text { slightly } \\
\text { Water soluble }\end{array}$ \\
\hline $\mathrm{N}_{2} \mathrm{O}_{3}$ & Dinitrogen trioxide & 3 & $\begin{array}{c}\text { Black solid water } \\
\text { soluble, decomposes } \\
\text { in water }\end{array}$ \\
\hline $\mathrm{NO}_{2}$ & $\begin{array}{c}\text { Nitrogen dioxide } \\
\mathrm{N}_{2} \mathrm{O}_{4}\end{array}$ & 4 & $\begin{array}{c}\text { Red-brown gas } \\
\text { dinitrogen tetroxide } \\
\text { decomposes in water }\end{array}$ \\
\hline $\mathrm{N}_{2} \mathrm{O}_{5}$ & $\begin{array}{c}\text { Dinitrogen } \\
\text { pentoxide }\end{array}$ & 5 & $\begin{array}{c}\text { White solid very } \\
\text { water soluble, } \\
\text { decomposes in water }\end{array}$ \\
\hline
\end{tabular}

At any temperature, $\mathrm{N}_{2} \mathrm{O}$ can be oxidised by $\mathrm{O}_{3}$ to produce molecular oxygen $\left(\mathrm{O}_{2}\right)$ and either $\mathrm{NO}$ or two NO molecules linked together as its dimer, dinitrogen dioxide $\left(\mathrm{N}_{2} \mathrm{O}_{2}\right)$. The $\mathrm{NO}$ or $\mathrm{N}_{2} \mathrm{O}_{2}$ is subsequently rapidly oxidised (in about two hours) to $\mathrm{NO}_{2}$. When the $\mathrm{NO}_{2}$ is hit by a photon of ionising radiation from sunlight, it produces an ozone molecule from oxygen $\left(\mathrm{O}_{2}\right)$ molecule. $\mathrm{N}_{2} \mathrm{O}$ is a "Greenhouse Gas" that, like carbon dioxide $\left(\mathrm{CO}_{2}\right)$, absorbs long wavelength infrared light to trap heat radiating from Earth, contributing to global warming [2].

\section{c. Source of NOx}

Automobiles and other movable sources contribute approximately half of the NOx emissions. Electric power plant boilers account for over $40 \%$ of NOx emissions from fixed sources. Furthermore, anthropogenic sources like industrial boilers, gas turbines, reciprocating spark ignition, and diesel engines in stationary sources, iron and steel mills, cement manufacturing, glass manufacturing, petroleum refineries, and nitric acid manufacturing contribute extensively to emissions. Lightning, forest fires, grass fires, trees, bushes, grasses, and yeasts are all natural sources of nitrogen oxides. The quantity of each oxide produced by these numerous sources vary. The anthropogenic sources are roughly depicted as
TABLE 2

SOURCES OF $\mathrm{NO}_{\mathrm{X}}$

\begin{tabular}{|c|c|c|}
\hline Mobile Sources & $\begin{array}{c}\text { Electric Power } \\
\text { Plants }\end{array}$ & Everything Else \\
\hline $50 \%$ & $20 \%$ & $30 \%$ \\
\hline
\end{tabular}

This chart depicts the emissions from our two main sources of NOx. We might be able to live with the rest if we could reduce NOx emissions from just the two leading categories. However, neither of these groups is likely to become zero in the near future. We cannot expect cars, trucks, buses, and aero-planes to vanish. The zeroemission vehicle is still under development and is not yet on the assembly line. In addition, social customs must alter before power use may be reduced.

There are two possibilities for NOx generation in all combustion. They are as follows:

1. Thermal NOx - The concentration of "thermal NOx" is determined by the molar concentrations of nitrogen and oxygen as well as the temperature of combustion.

2. Fuel NOx - Nitrogen-containing fuels (e.g., coal) produce "fuel NOx" as a result of the oxidation of the fuel's already-ionized nitrogen [2].

\section{d. NOx effects on environment}

Because NOx is transparent to most light wavelengths (although $\mathrm{NO}_{2}$ is brownish and the uncommon $\mathrm{N}_{2} \mathrm{O}_{3}$ is black), they allow the great majority of photons to pass through and so have a lifetime of at least several days. Because $\mathrm{NO}_{2}$ is recycled from $\mathrm{NO}$ by the photoreaction of VOC to produce additional ozone, $\mathrm{NO}_{2}$ appears to have a longer life span and is capable of travelling extended distances before producing ozone. Weather systems typically traverse over the earth's surface, allowing atmospheric effects to extend for hundreds of kilometres downwind. This was mentioned in EPA papers more than two decades ago. According to these reports, each large city on the East Coast has an ozone plume that stretches more than a hundred miles out to sea before concentrations drop to 100 parts per billion (ppb). 
Another storey mentioned the same thing happening in St. Louis. As a result, the problem was not limited to the seashore. Because ozone has a short lifetime in pure air, this phenomenon is a measure of the effect and persistence of both VOC and NOx [2].

\section{A. Statement of the Problem}

Air pollution causes a variety of respiratory disorders, including asthma, lung cancer, chest pain, congestion, throat inflammation, cardiovascular ailments, and respiratory diseases. This contaminated environment not only harms human health, but it also harms plant development, reduces soil fertility, and modifies soil structure. The primary contributors to this pollution are dust particles of various sizes, NOx gases that may contain microscopic particulates or liquid droplets small enough to enter the lungs and cause serious health concerns. So, in order to eliminate this effect, a little effort has been made to reduce the horrible effect of pollution and improve human existence by humanizing the condition of the environment.

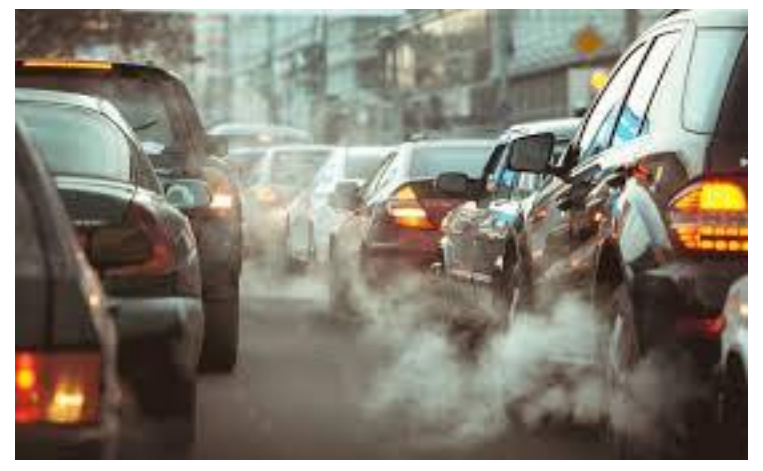

Fig 1. Air pollution

\section{B. Objective of the Work}

The primary goal is to lessen the detrimental effects of polluting gases and improve the quality of the atmosphere's air. Poisonous fumes, which are extremely detrimental to both human and animal life, must be removed. The project's goal is to create a low-cost air pollution management device that can sustain good air quality. As a result, we created this gadget, which can maintain air quality while operating at a cheaper cost.
The project's goal is to lower the presence of NOx in the atmosphere by up to $60 \%$.

The project's concept is that a single device will regulate the overall effect of pollution by separating dust and NOx emissions, both of which are extremely damaging to humans. This device will collect dust and other polluting gases from the environment and separate them. Finally, it will lessen the damaging effect of NOx gases by chemical reaction, leaving clear, clean gases in the air. An air pollution control device can be deployed anyplace to maintain pollution standards and improve human life.

\section{RESEARCH GAP ANALYSIS}

K. Chithambaramasari et al. [3] examined injection of aqueous urea solutions in the exhaust for NOx reduction in a single cylinder low workload DI diesel engine. Several types of urea solution concentrations ranging from $10 \%$ to $40 \%$ by weight, as well as varied flow rates of urea solution ranging from $250 \mathrm{ml} / \mathrm{hr}$ to $750 \mathrm{ml} / \mathrm{hr}$, were examined using vanadium as a catalyst, which increases chemical reactions even at a lower temperature of $190^{\circ} \mathrm{C}$. The flow rate of urea solution should be fixed and maintained constant for a set of experiments by setting the three-way control valve and selecting the needle. The results reveal that an optimal flow rate of $0.75 \mathrm{lit} / \mathrm{hr}$ with a maximum NOx reduction of 27.46 percent was achieved.

S. Ghosh et al. [4] explored injection of aqueous urea solutions in the tail pipe of a diesel engine for $\mathrm{NO}_{2}$ reduction in a four stroke, single cylinder, water cooled, constant speed diesel engine. Four observations were obtained for the exhaust emission NOx analysis of urea solution concentrations ranging from 0 to $30 \%$ by weight with varying flow rates of urea solution as reductant by fitting marine ferromanganese nodule as SCR catalyst. It was revealed that a reduction of $64 \%$ in NOx was obtained.

Ioannis Gekas et al. [5] discussed the selection of catalyst types for lowering NOx emissions to EuroV 
levels. A unique Urea injection system is also shown, which is based on a mass-produced digital dosage pump paired with an electronic control unit designed specifically for controlling the Urea-SCR process onboard cars. It is demonstrated that employing 30 litres of 130 cpsi catalysts for a 12-diesel engine, it is possible to achieve a NOx conversion of more than $80 \%$ and an ammonia slip of less than $10 \mathrm{ppm}$. By raising the cell density to $300 \mathrm{cpsi}$, the catalyst volume can be reduced by two-thirds to 20 litres for the same engine.

\section{A. Gap Areas of Research}

There are little gaps that we have noticed during our project work. As a result, we have chosen to bridge that gap in our future. Then we will be able to provide a proper answer to our society's problem of dirty air, which is rapidly becoming one of the most serious issues confronting both humans and the entire planet. The gaps that we face are described more below.

- A full solution to the problem of air pollution, i.e., a chemical capable of removing all pollutant types such as NOx, SOx, HC, CO, and others.

- A single filter capable of absorbing all pollutants and releasing pure air into the atmosphere.

- We attempted to include sensors within the gadget, but this scaled model did not allow us to do so.

- We are looking to create an Android app that will allow us to monitor its performance as well as its requirements.

\section{EXPERIMENTAL SETUP}

\section{A. Apparatus required}

The complete system can be divided into three important segments, which is needed for the working of the system, these are input section, device and output section. The input section is mainly consisting of sources of NOx i.e., the output of the automobiles and a diffuser, which is used for slow down the velocity of the polluted air, before enter to the device.

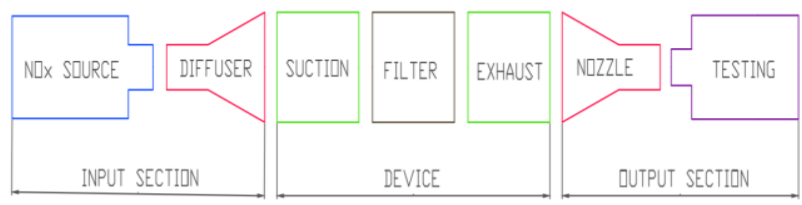

Fig 1. Experimental Arrangement

The major and most essential section of the system, which is our main task for this project, is the device, which is divided into three parts: suction, filter, and exhaust. In this part, the project's goal is achieved.

The third component of the system is the output section, which is utilized for testing the device and determining the system's performance. The output part consists of a nozzle and testing equipment for determining the quality of air at the output. The entire system is made up of these three components.

\section{B. Component of the Device}

The gadget is made up of various components, which are joined together to make the entire system. The specifics of those parts are provided below.

Upper Section: The suction fan is housed in the upper part of the device, and the sucked air is passed through it. Figure 2 depicts this.

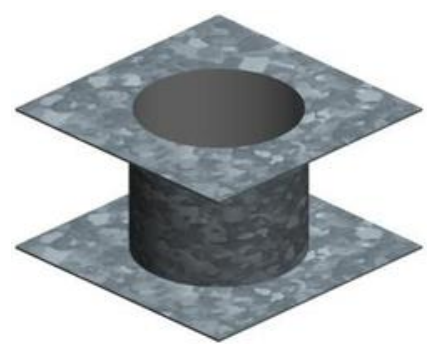

Figure 2: Upper part

Suction Fan: A suction fan is used to suck filthy air from the atmosphere, which is primarily emitted by automobiles and factories.

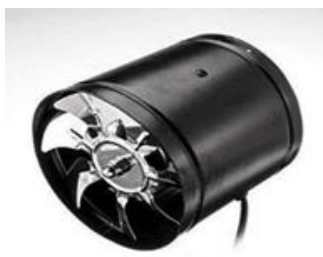

Figure 3. Suction Fan 
Middle Part: In middle portion of the device is used to hold the filter in it. The action to remove NOx is taken place in this portion.

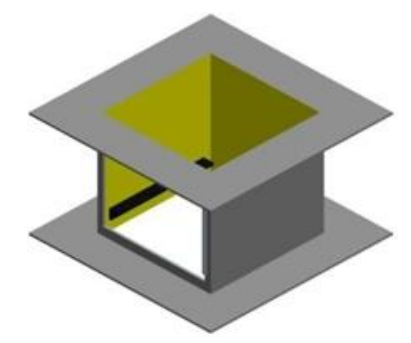

Figure 4. Middle Part

Filter: The paper filter is used to filter the air and also hold the chemical which reacts with NOx.

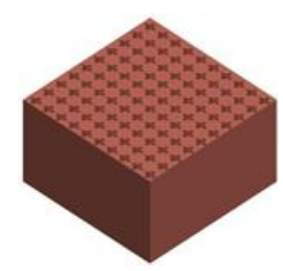

Figure 5. Filter

Lower Part: The lower part of the model consists of an exhaust fan which helps to escape the filtered air to the atmosphere.

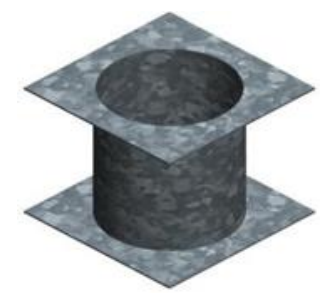

Figure 6. Lower Part

Exhaust fan: An exhaust fan is fitted at the lower portion of the device inside the lower part, which helps to the NOx free air to release into the atmosphere easily with the pressure greater than the atmospheric pressure.

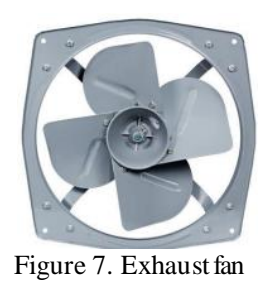

Stand: Four stands are provided to support and connect all the three parts of the body structure and also give stability to the body.

Figure 8. Stand
These all parts are assembled together and develop the model of our project i.e., the device for removing NOx present the exhaust of automobiles.

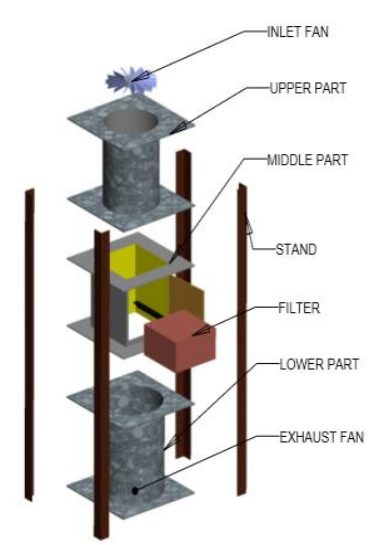

EXPLODED VIEW

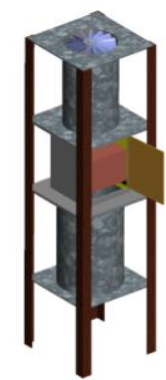

ASSEMBLE MODEL
Figure 9. Model of the Device

a) Specification of Parts

Three main parts of this device are suction fan, exhaust fan and the filter. Their specifications are given below Suction Fan Specification

$\begin{array}{ll}\text { Air extraction: } & 1080 \mathrm{~m}^{3} / \mathrm{hr} \\ \text { Fan speed: } & 2800 \mathrm{rpm} \\ \text { Voltage: } & 220 \mathrm{~V} \\ \text { Power: } & 40 \mathrm{~W}\end{array}$

\section{Exhaust Fan Specification}

$\begin{array}{ll}\text { Air extraction: } & 320 \mathrm{~m}^{3} / \mathrm{hr} \\ \text { Fan speed: } & 2000 \mathrm{rpm} \\ \text { Voltage: } & 220 \mathrm{~V} \\ \text { Power: } & 18 \mathrm{~W}\end{array}$

\section{Filter Specification}

Material: Honey comb like paper filter

Volume: $\quad 150 * 150 * 80 \mathrm{~mm}^{3}$

\section{b) Relationship between Different Parts}

Each and every part of this model is developed after successful calculation of the size and shape of the parts in ANSYS. So that it become possible to develop the relationship between every parts.

Diameter of Inlet fan $(\mathrm{Di})=150 \mathrm{~mm}=0.15 \mathrm{~m}$

Diameter of Exhaust fan $($ Do $)=180 \mathrm{~mm}=0.18 \mathrm{~m}$

$$
\mathrm{Do}=1.2 * \mathrm{Di}
$$




$$
\begin{aligned}
& \text { Suction area }(\mathrm{Ai})=\left(3.14 * \mathrm{Di}^{2}\right) / 4 \\
&=0.0177 \mathrm{~m}^{2} \\
& \text { Exhaust area }(\mathrm{Ao})=\left(3.14 * \mathrm{Do}^{2}\right) / 4 \\
&=0.0254 \mathrm{~m}^{2} \\
& \text { Ao }=1.44 * \mathrm{Ai}
\end{aligned}
$$

Suction air flow / $\mathrm{sec}=1080 / 3600$

$$
=0.3 \mathrm{~m}^{3} / \mathrm{sec}
$$

Exhaust air flow / $\mathrm{sec}=320 / 3600$

$$
=0.088 \mathrm{~m}^{3} / \mathrm{sec}
$$

Filter volume $=0.0018 \mathrm{~m}^{3}$

\section{c) Comparison between different Methods}

Method 1: Reducing Temperature: Lowering the temperature of combustion implies avoiding the stoichiometric ratio, or the exact ratio of chemicals that enter the reaction. Essentially, this method dilutes calories by using an excessive amount of fuel, air, flue gas, or steam. Different types of this technology are used in combustion controls, and they differ for fuels with high and low nitrogen content. The net stoichiometric ratio can be used to understand NOx control from the combustion of high nitrogen content fuels. The control of NOx from low nitrogen fuel combustion can be visualized as lean versus rich fuel/air ratios. In any case, this technique avoids the optimal stoichiometric ratio since it produces higher temperatures, which result in higher concentrations of thermal NOx [2].

Method 2: Reducing Residency Time: Internal combustion engines can reduce resident time at high combustion temperatures by adjusting ignition or injection timing. This can also be accomplished in boilers by restricting the flame to a restricted region where the combustion air produces flue gas. This is immediately followed by the injection of fuel, steam, more combustion air, or recirculating flue gas. The vast majority of nitrogen is not ionised due to the short residence time at peak temperature. This has nothing to do with a flue gas's overall residence time in a boiler.
Method 3: NOx Oxidation: This technique purposely enhances the valence of the nitrogen ion in order to allow water to absorb it; it is based on the higher valence's enhanced solubility of NOx. This is accomplished by using a catalyst, injecting hydrogen peroxide, creating ozone within the air flow, or injecting ozone into the air flow. Non-thermal plasma can be used to oxidise NOx in the absence of a reducing agent. A scrubber must be added to the process to absorb N2O5 emissions into the atmosphere. Any resulting nitric acid can be neutralized by the scrubber liquid and sold as calcium or ammonia salt, or it can be collected and sold to customers as nitric acid [2].

Method 4: Nitrogen removal from combustion: This is accomplished by removing nitrogen as a reactant from the combustion process, either by using oxygen instead of air in the combustion process or by employing ultra-low nitrogen content fuel to produce less fuel NOx. When nitrogen is removed by employing oxygen, it produces a relatively powerful flame that must be subsequently and appropriately dampened. Although Method 2 can rapidly lower the temperature to avoid the formation of excessive NOx, it cannot completely eliminate nitrogen oxides if air is used as the quench medium. Hot flue gas heats the air required to quench it, which produces some thermal NOx. Because air is 80 percent nitrogen, this strategy also entails minimising the net surplus air consumed in the combustion process. Using ultra-low-nitrogen-content fuels in conjunction with oxygen can practically eliminate fuel and trigger NOx emissions.

Method 5: Sorption (both adsorption and absorption): Flue gas treatment with sorbents such as ammonia, powdered limestone, aluminium oxide, or carbon can remove NOx and other contaminants, primarily sulphur. There have been successful initiatives to commercialize sorption products. This method has been used in the combustion chamber, flue, and baghouse. Despite the fact that the use of carbon as an adsorbent has not resulted in a marketable product, it is occasionally employed to control NOx emissions. The sorption process is 
commonly associated with the use of a dry sorbent, but slurries have also been utilised. To remove the sorbent, this process employs either adsorption or absorption, followed by filtration and electrostatic precipitation [2].

Our Approach: NOx Reduction through Chemical Means: To remove oxygen from nitrogen oxides, this procedure employs a chemically reducing material, i.e. reversal of oxidisation. Selective Catalytic Reduction (SCR), which employs ammonia, Selective Non-Catalytic Reduction (SNCR), which uses ammonia or urea, and Fuel Reburning are other examples (FR). Non-thermal plasma, a new technology, chemically decreases NOx when combined with a reducing agent. All of these methods aim to chemically lower the valence level of nitrogen to zero after it has risen. This approach is also used in several low-NOx burners [6].

We use liquid urea as our chemical in this procedure to remove NOx from the air flowing out of the automobile. Poisonous fumes, which are extremely detrimental to both human and animal life, must be removed. It can preserve air quality while operating at a lesser cost.

\section{RESEARCH METHODOLOGY}

\section{A. Solving Problems in Human Life}

Because we share everything on Earth with every living thing, what happens in one region impacts everything else, no matter how far away it is. Pollution, or the introduction of various types of waste products into our environment, has a negative impact on the ecosystem.

Nowadays, one of the most serious issues in human life is the deterioration of air quality as a result of mobilization and industrialization. When we burn the fossil fuels we use every day, we emit a wide range of chemicals into the atmosphere. We need air to breathe in order to live, and what we breathe has a direct impact on our health.

We live in an ecosystem in which the actions of one can have a ripple effect on the actions of many. Depending on the action, this might be a positive or a bad thing. Our blunders have poisoned the environment in which we live, and we are finally waking up to the fact. We're attempting to repair the damage. The good news is that every good deed counts. Your tiny contribution to a greener environment can start a healing ripple effect. We can still rescue what remains of our natural resources and make the world a better place to live for our children and grandchildren.

Air pollution is a main concern in the modern world, with serious toxicological consequences for human wellbeing and the environment. It contains a variety of emission sources, but motor vehicles and industrial processes account for the majority of air pollution. Particle pollution, ground-level ozone, carbon monoxide, sulphur oxides, nitrogen oxides, and lead are the six primary air pollutants, according to the World Health Organization. Long-term and short-term exposure to air dispersed toxicants has varied toxicological effects on humans, including respiratory and cardiovascular disorders, neuropsychiatric problems, eye irritation, skin diseases, and long-term chronic diseases like cancer. Several studies have found a direct link between poor air quality and an increase in morbidity and mortality, primarily from cardiovascular and respiratory disorders. Asthma, lung cancer, ventricular hypertrophy, psychiatric difficulties, autism, retinopathy, prenatal growth, and low birth weight are all considered key environmental risk factors [7] [8] [9].

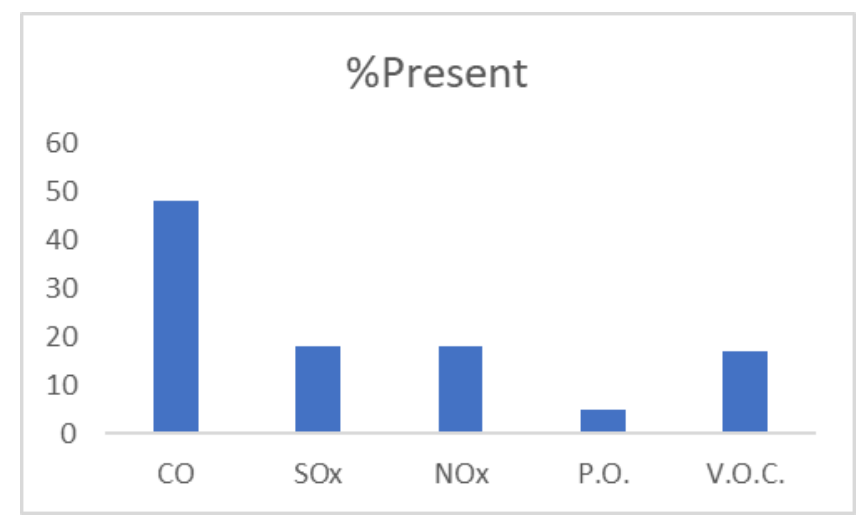

Figure 10. WHO Report on Pollutant

The effects of air pollution on living organisms will not only affect human and animal health, but will also affect the entire environment. Different geographical 50

$\triangle \mathbf{R A M E}$ PUBLISHERS 
conditions, global temperature changes, and environmental variances all have an impact on human fitness and the environment, as well as animal life.

Nitrogen oxides are significant air pollutants that may raise the risk of respiratory illnesses. They are primarily generated by motor engines and consequently contribute to traffic-related air pollution. They are deep lung irritants that, if inhaled in large quantities, can cause pulmonary edoema. They are normally less hazardous than O3, however NO2 can cause significant toxicological issues. T-lymphocytes, particularly CD8+ cells and natural killer cells, have been demonstrated to be affected by $2.0-5.0$ ppm exposures, which play a crucial role in host defences against viruses. Despite the fact that these levels are high, epidemiologic studies show that NO2 has an influence on respiratory illness rates in children.

The most common problem of nitrogen oxide intoxication is coughing and wheezing, although other symptoms include eye, nose, or throat pain, headache, dyspnea, chest pain, diaphoresis, fever, bronchospasm, and pulmonary edoema. In another paper, it is claimed that nitrogen oxide levels between 0.2 and $0.6 \mathrm{ppm}$ are safe for humans [10].

\section{a) Effects of Pollutant}

Air pollution has become a major issue in recent decades, with serious toxicological consequences for human fitness and the environment. Pollution sources range from small units of cigarettes and natural sources such as volcanic activity to massive volumes of emission from automotive motor engines and industrial activities. The long-term consequences of air pollution on the development of diseases such as respiratory infections and inflammations, cardiovascular dysfunctions, and cancer are generally acknowledged. As a result, air pollution is linked to millions of deaths globally each year. A recent study found a link between male infertility and air pollution. Air pollution has recently formed in developing countries as a result of industrial activity, and the number of emission sources, such as improper automobiles, has increased.

The standard level of several conventional air contaminants is described, with the values defined as air quality norms that protect public welfare. As is obvious, the majority of air pollution is caused by the use of fossil fuels. Air pollutants are also categorised as human or natural based on their source of emission. Anthropogenic air pollution comes as a result of industrial and agricultural operations, transportation, and energy acquisition. Natural pollutant emissions come from a variety of sources, including volcanic activity, forest fires, sea water, and so on.

- Health dangers: In terms of health hazards, air toxicants are defined as any odd suspended substance in the air that creates difficulties in the normal function of human organs. The main harmful consequences of air pollution exposure, according to existing data, are primarily on the respiratory, cardiovascular, dermatologic, neuropsychiatric, hematologic, immunologic, and reproductive systems. However, longterm molecular and cell damage may cause a variety of malignancies. On the other hand, even low levels of air toxicants have been demonstrated to be hazardous to vulnerable groups such as children and the elderly, as well as individuals suffering from respiratory and cardiovascular disorders.

- Respiratory disorders: Because most pollutants go into the body via the airways, the respiratory system is the first line of defense in the beginning and progression of diseases caused by air pollutants. They induce varying degrees of harm in the respiratory system depending on the amount of pollutant inhaled and accumulation in target cells. The initial consequence in the upper respiratory system is inflammation, particularly in the trachea, which causes voice problems. Air pollution is also regarded as a significant environmental risk factor for some respiratory disorders such as asthma and lung cancer. Air pollutants, particularly PMs and other respirable compounds such as dust, $\mathrm{O}_{3}$, and benzene 
cause substantial respiratory tract damage. Asthma is a respiratory disorder that can develop as a result of being exposed to air toxicants. Some studies have found links between traffic-related and/or industrial air pollution and an increased risk of COPD. The treatment of respiratory ailments caused by air pollution is comparable to that of other hazardous chemicals that cause respiratory problems.

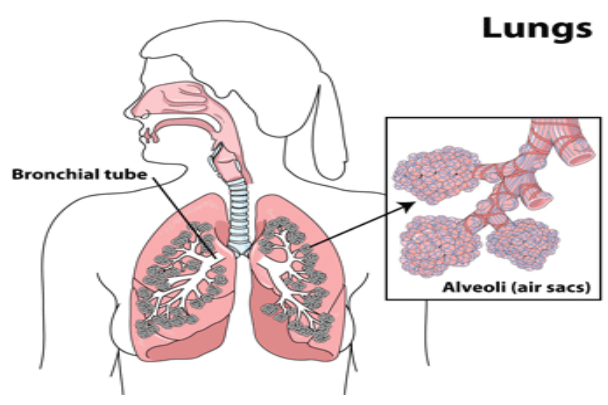

Figure 11. Effects on Human

- Cardiovascular dysfunctions: Numerous experimental and epidemiologic researches have discovered a direct association between air pollution and cardiac-related diseases. Changes in white blood cell counts have also been connected to air pollution, which may have an impact on cardiovascular functions. A study utilising animal models, on the other hand, suggested a close relationship between hypertension and exposure to air pollution. High NO2 levels in traffic-related air pollution have been associated to right and left ventricular hypertrophy. Standard cardiovascular disease treatment should be carried out in conjunction to antidote therapy, which is only accessible for a few hearts hazardous substances like $\mathrm{CO}$.

- Neuropsychiatric complications: The relationship between harmful substances in the air and the neurological system has long been questioned. However, it is now believed that these deadly compounds are toxic to the neurological system. The neurotoxic effect of air pollution on the nervous system includes both neurological and psychiatric illnesses. Neurological impairment, especially in infants, can have disastrous consequences. Psychiatric disorders, on the other hand, will result in hostility and antisocial behaviour. Air pollution has been linked to neurobehavioral hyperactivity, criminal behaviour, and age-inappropriate behaviour, according to recent study. According to study, air pollution has also been associated to an increased risk of neuroinflammation, Alzheimer's, and Parkinson's disease. According to several studies, animosity and anxiety in megacities are linked to high levels of air pollution.

- Other long-term consequences: The skin is the body's first line of defense against a foreign virus or infectious agent, and it is the first organ to be polluted. The skin is a pollution target organ, with absorption of pollutants from the environment equal to respiratory uptake. According to skin study, traffic-related air pollutants such as PAHs, VOCs, oxides, and PM have an impact on skin ageing and cause pigmented patches on the face [11].

\section{b) Work Involving Air Pollution}

Air pollution has a significant impact on human health, triggering and inducing a variety of diseases that result in high morbidity and mortality, particularly in developing nations such as India. As a result, controlling air pollution is critical and should be at the top of the government's priority list. These countries' policymakers and legislators must update all air pollution laws and regulations. A powerful environmental protection agency must lead the coordination of several agencies involved in air pollution. A successful environmental protection agency should have adequate budgets for administration, research and development, monitoring, and full environmental control, including air pollution. As a result, we have chosen to focus on improving the air quality and providing a remedy [6].

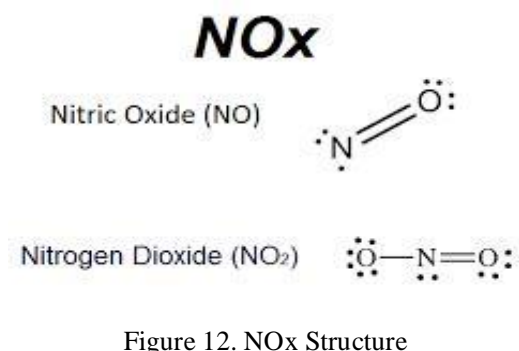

Figure 12. NOx Structure 
c) Work Towards Removing NOx

We chose to focus on reducing NOx from the air coming out of autos after identifying a problem in human life caused by air pollution. As we all know, this is one of the most pressing issues confronting humanity's future, so we took this obligation as an opportunity and began working to discover a solution for one of the major pollutants present in the air, which comes from automobiles as well as factories. Nitrogen Oxides (mostly NO and NO2), often known as NOx, are a class of extremely reactive gases that include nitrogen and oxygen in varying concentrations and chemical configurations. The majority of nitrogen oxides are colourless and odourless.

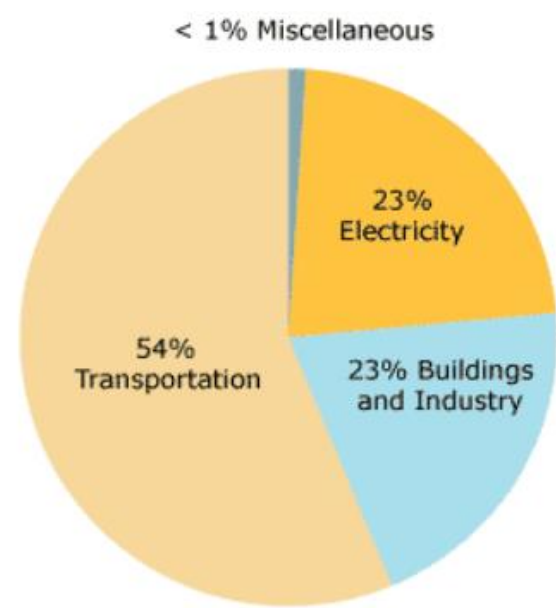

Figure 13. Manmade Sources of NOx

When the nitrogen in fuels reacts with the extra oxygen in the air, fuel NOx is generated. Fuel NOx is a serious issue in the combustion of oil and coal, accounting for up to $50 \%$ of total emissions when burning oil and up to $80 \%$ of total emissions when burning coal. So we have mostly concentrated on NOx emissions from automobiles and are working to develop a way to reduce pollution levels, which are steadily increasing with urbanization [12].

\section{B. Research Paper Study}

Study of research paper is the basic step before starting the wok, so after finalize our aim of the project, we have started our research work to finding solution for the NOx removal. In this way, we have studied different research paper, journals, and books as well and initially pointed out some methods for removing NOx from the polluted air, coming out from the different sources. So after making these all studied, we have decided to develop a device which will be based on chemical reduction process.

\section{Model Development}

After research paper study we decide the principal of working of our project and it is the most important step that the model should follow the principal of working. So, we have a big responsibility to develop a design to fulfil the basic principle. So, in this way we use CREO 4.0 and ANSYS 17.1 to convert our concept into a model. Before developing a physical model, it is very important that we finalize suitable dimensions for the model. So, firstly we have designed our model in CREO and after that we have tested the same model in ANSYS and got some results. We have built certain relationships between the parts based on those results, so that when we develop our physical model with the right configuration, we will be sure in our design.

a) Model Configuration and Specifications

All of the model's components are configured in a continuous series in our project. The model begins with the inlet section, which houses an inline duct fan with a speed of $2800 \mathrm{rpm}$ and is directly connected to the second and most important middle portion of the model, which houses the chemically wetted filter and is where the actual chemical reaction and transformation from NOx to AntiNOx occurs. This middle section of the device is immediately connected to the third and final section of the device, the outlet section, where an exhaust fan with a speed of $2000 \mathrm{rpm}$ is installed to remove the clean gas to the atmosphere.

\section{i. Design of the Device using CREO 4.0}

We have completed our designing portion of the model in CREO 4.0 and draw all the parts of the model with dimensions, are shown below 


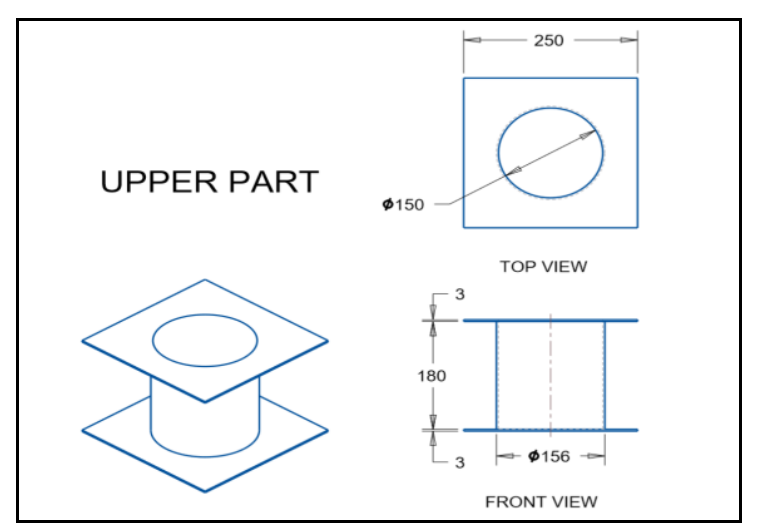

Figure 14. Upper Part Dimensions

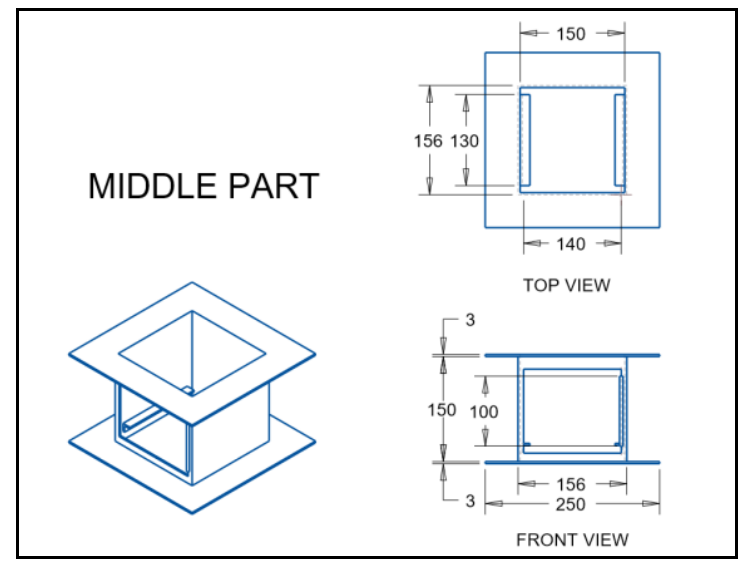

Figure 15. Middle Part Dimensions

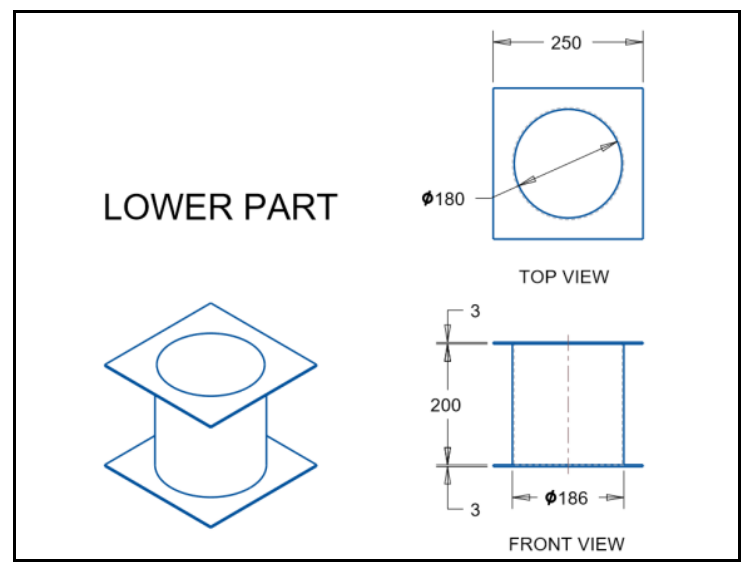

Figure 16. Lower Part Dimensions

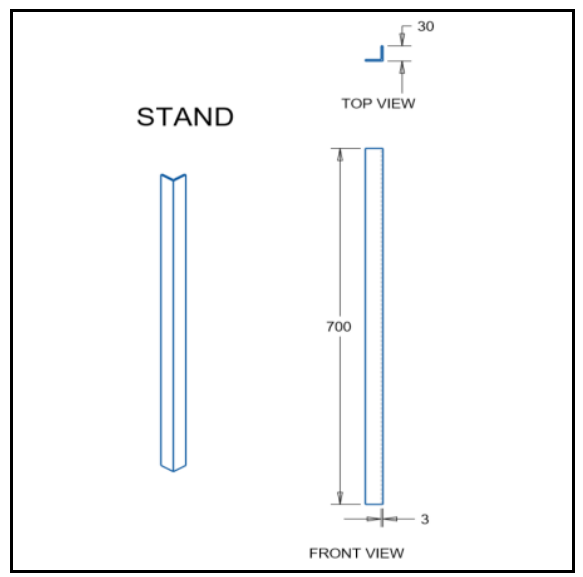

Figure 17. Stand Dimensions

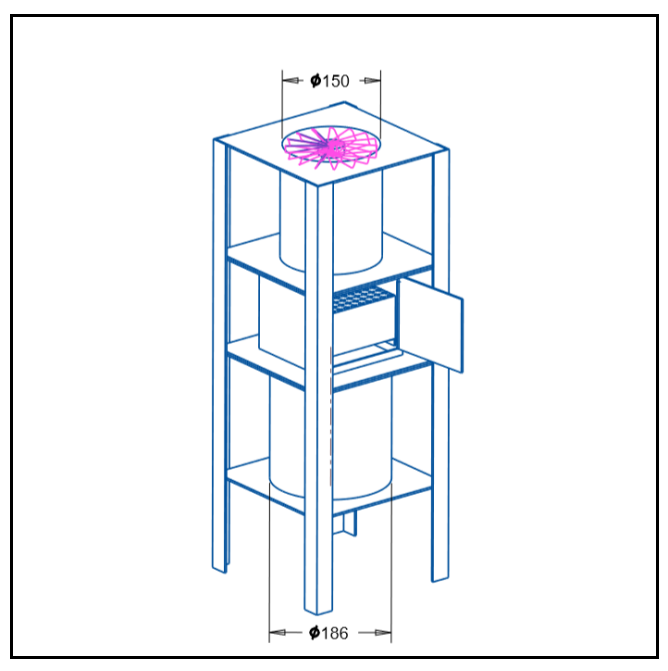

Figure 18. Assembly of all parts

In this way, our model has been designed. Our next step is that to check the performance of the device with the help of velocity and pressure analysis in ANSYS 17.1. In that, we simulate our model and as we found the data, then we have developed the relation among the parts. In this way, we have reached out to our final dimensions of our model.

ii) Velocity and Pressure Analysis using ANSYS 17.1

The ANSYS workbench platform serves as the foundation for the industry's most comprehensive and indepth portfolio of advanced engineering simulation. A novel project schematic view connects the whole simulation process, leading the user through even the most complex Multiphysics analyses with drag-and-drop ease. The ANSYS Workbench Platform enables exceptional productivity, enabling simulation-driven product development, with bi-directional $\mathrm{CAD}$ connectivity, an automated project level update mechanism, ubiquitous parameter management, and integrated optimization tools.

ANSYS Workbench supports bidirectional connection with all major CAD systems in Geometry Interfaces, allowing for fast simulation-driven design decisions. ANSYS Meshing streamlines the analysis process and helps ensure reliable solutions by providing a range of meshing options, from simple automatic meshing to carefully constructed meshing. ANSYS Design Modeller 
bridges the gap between CAD data and simulation by providing analysis-specific geometry modelling tools. ANSYS Design Xplorer supports Design of Experiments, goal-driven optimization, $\min / \max$ search, and even Six Sigma analysis to fully harness the potential of parametric analysis.

To simulate our model in ANSYS and do flow analysis, we must first create the real component of the model in solid form through which the air will pass. So, we created the internal component of the model in CREO and used that solid part of the model to perform the velocity and pressure analysis in ANSYS Workbench. This simulation was done in a series of steps. In those steps, we must adhere to the right simulation method as well as the boundary conditions.

Step 1: Design solid model of the internal portion in CREO, through which air will be passing and save it in “.igs” form to import in ANSYS Workbench 17.1.

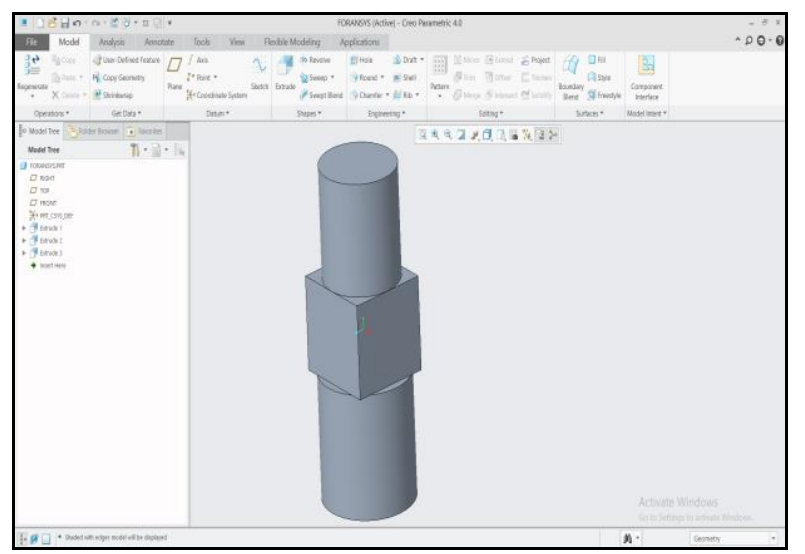

Figure 19. Solid internal portion

Step 2: To start simulation in ANSYS Workbench, firstly we have drag-and-drop the Fluid flow CFX from the analysis system.

Step 3: Import Geometry from the files and delete all the default domain.

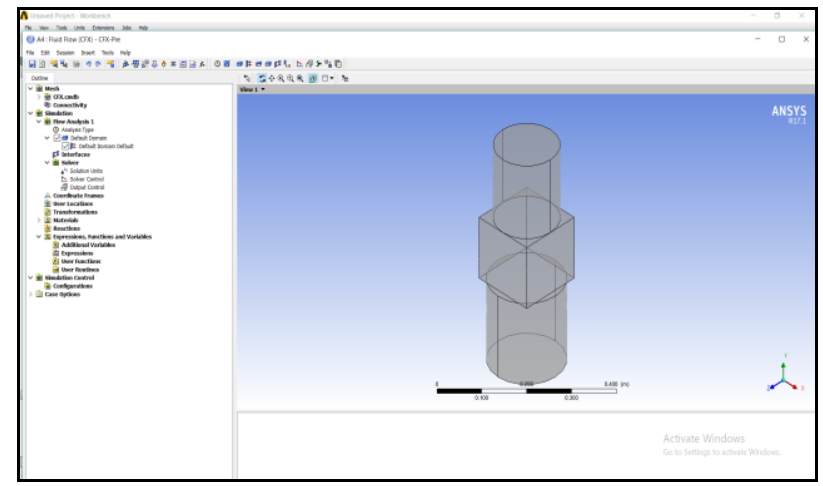

Figure 20. Import Geometry

Step 4: Meshing the model. In this step complete object is divided into many sub elements, which is necessary for calculate accurate results.

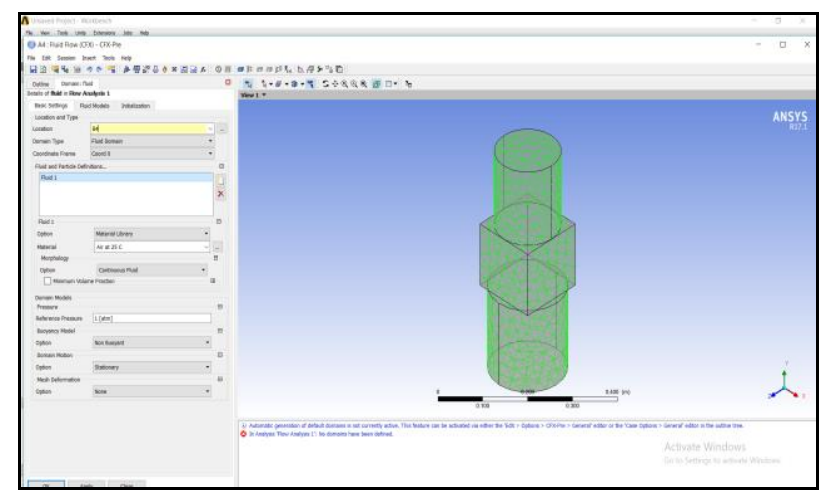

Figure 21. Meshing

Step 5: Setup the boundary conditions at the inlet as well as at the outlet.

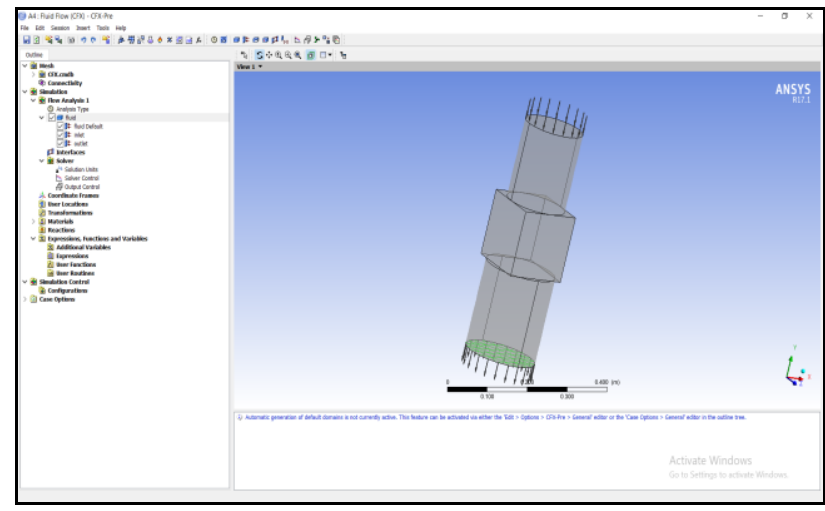

Figure 22. Setup boundary condition

Step 6: Solution stage, in this step ANSYS Workbench provide self-calculated values, on the basis of boundary conditions. 


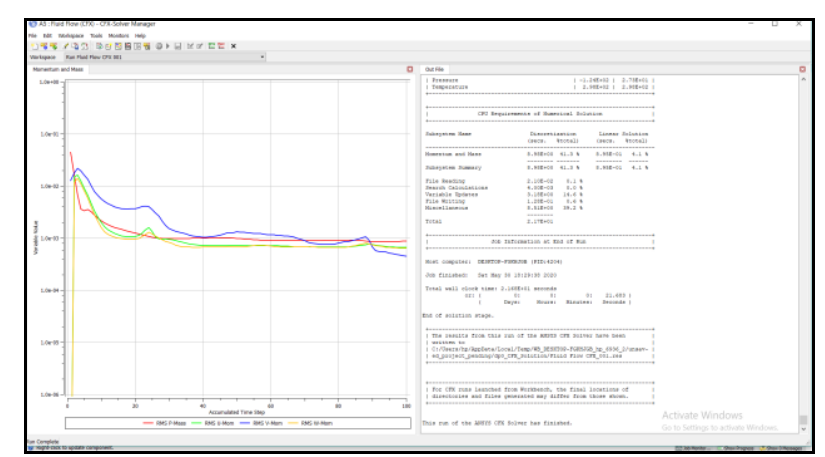

Figure 23. Solution

Step 7: Result, on the basis of solution ANSYS provide results as per requirement and in different forms.

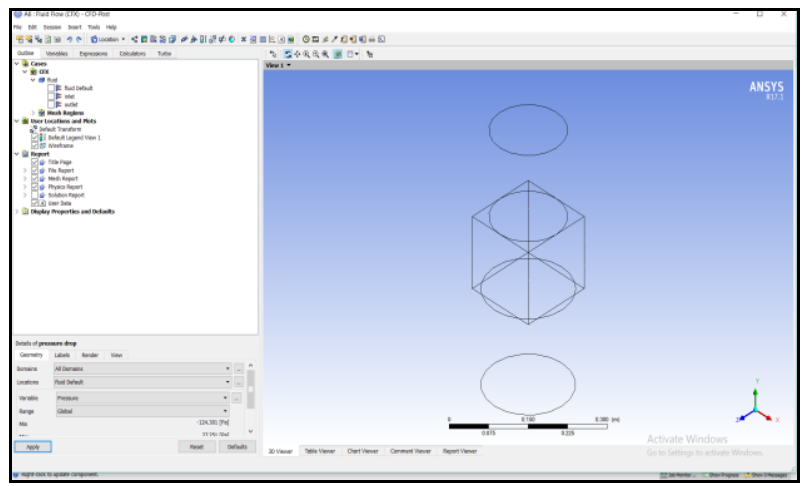

Figure 24. Results

Step 8: Pressure distribution in the model is shown by the contour plot, and it is as per our requirement.

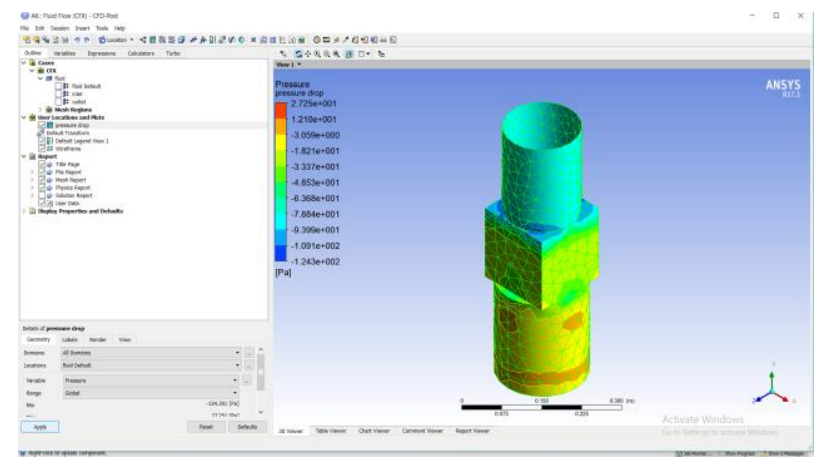

Figure 25. Pressure Distribution

Step 9: Velocity distribution in the form of streamlines.

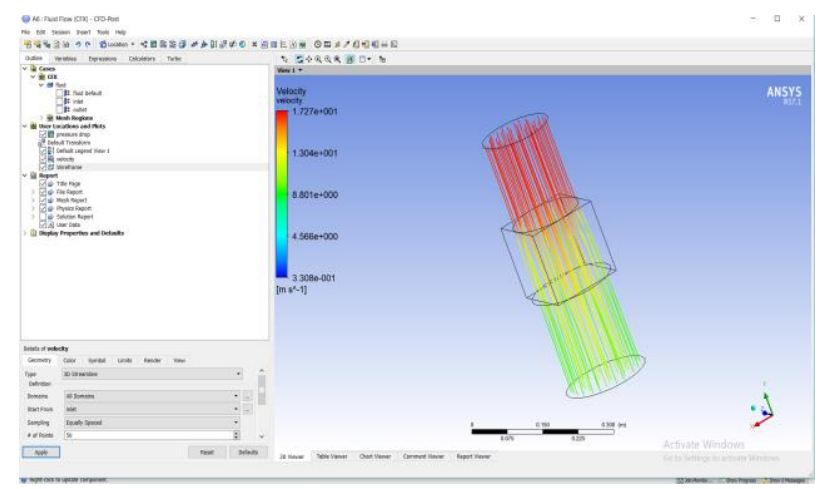

Figure 26. Velocity distribution

\section{iii. Actual Model with Design Parameters}

After we completed all of our work, the following stage was to create a physical model for the project that adhered to all of the factors that we had taken into account during the model's creation. So, in this manner, we began our work on the construction of a physical model that we referred to as a device for regulating air pollution by removing NOx present in the air flowing out of automotive exhaust.

We began by preparing the outside body of each device part with sheet metal and then assembled all of the parts to form the model's overall structure.

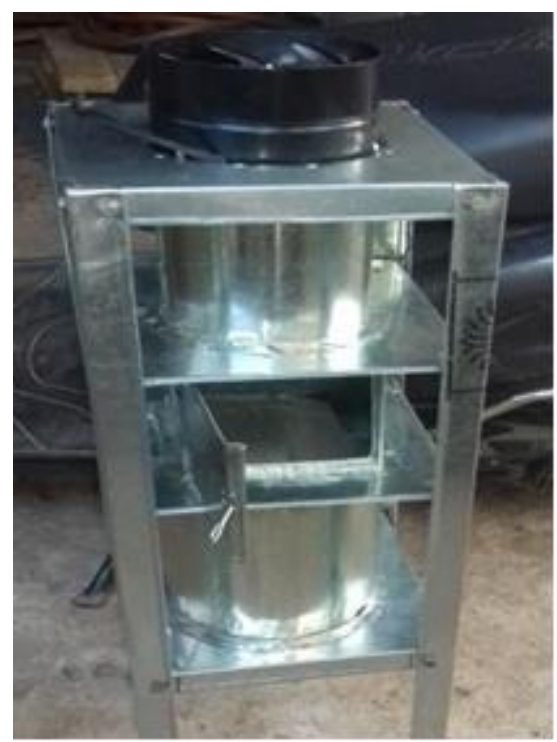

Figure 27. Sheet Metal body

After that, we assembled all of the parts, including the sheet metal body, inline duct fan at the inlet, exhaust fan at the outlet, and steel net at the top to prevent particulate matter. As a result, we created our device to regulate NOx and plugged all leaks, allowing us to avoid needless air inlet and outlet in the device. Then, we tested our device for pressure and velocity distribution. Then we went on to the chemical and filter work. So that we can achieve our project's goal of providing a solution to the society's air pollution problem.

\section{iv. Chemical Reaction and Filter}

It is critical that the chemical and filter utilised for the device be appropriate in order to get the best performance out of it. So, after conducting all of our study, we decided 
to use liquid urea ( $\mathrm{NH} 2 \mathrm{CONH} 2)$ as a chemical for testing the device, which has also been employed in selective catalytic systems, and it has been demonstrated that liquid urea has the potential to remove NOx from polluted air. The chemical reactions that occur during testing are explained further below.

NOx is found in the form of -

$2 \mathrm{NO}+\mathrm{O}_{2} \longrightarrow 2 \mathrm{NO}_{2}$

Nitric acid is form in liquid phase -

$2 \mathrm{NO}_{2}+\mathrm{H}_{2} \mathrm{O} \longrightarrow \mathrm{HNO}_{2}+\mathrm{HNO}_{3}+\mathrm{O}_{2}$

Nitric acid reacts with liquid urea-

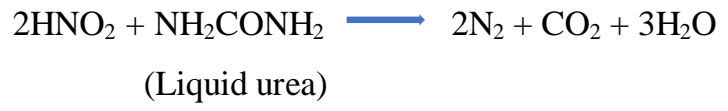

The filter is the second most significant factor in describing the device's performance, and we chose a honeycomb-like paper filter. This is something new and has never been utilised in this type of work, which is quite inexpensive and widely available on the market. As a result, it is also a component of our low-cost pollution control device, and we will conduct additional testing with this filter in the future to see if it can remove other pollutants as well.

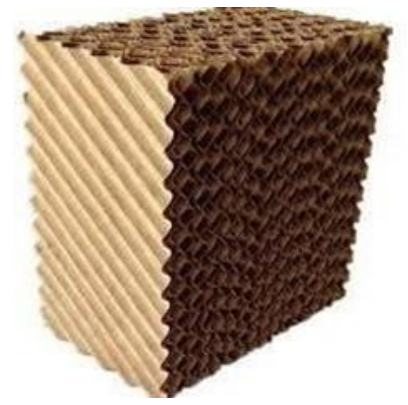

Figure 28. Honeycomb Filter

b) Working

Our device operates on the chemical reduction principle. We used liquid urea as our chemical in this procedure to remove NOx from the air coming out of the car. Poisonous fumes, which are extremely detrimental to both human and animal life, must be removed. It can preserve air quality while operating at a lesser cost. To remove oxygen from nitrogen oxides, this procedure employs a chemically reducing material, i.e., reversal of oxidization. Selective Catalytic Reduction (SCR), which employs ammonia, and Selective Non-Catalytic Reduction (SNCR), which uses ammonia or urea, are two examples. All of these methods aim to chemically lower the valence level of nitrogen to zero after it has risen. This approach is also used in several low-NOx burners. The device's operation is described further down.

- Initially, a suction fan will suck filthy air from a vehicle's exhaust. The sucked polluting gas will pass through the separator / intern filter, separating the safe NOx gas from the air.

- The filter will be chemically wetted, and the resulting chemical activity will transform NOx gases into non-polluting gases as they pass through the separator.

- Clean gas will pass through the lower area of the device, and liquid mixed dust will fall into the bottom section of the filter section.

- The outlet flow pressure will force the flow into the atmosphere, and clean air will exit the chamber through the bottom exhaust port. The chamber will be cleaned at regular intervals.

- A special filter material must be chosen to store the chemicals for longer periods of time while maintaining appropriate porosity to allow for $\mathrm{NOx}$ gas change as a result of chemical action and flow stream precision.

- Appropriate chemical must be chosen for the direct chemical reaction that converts toxic gases into nonpoisonous gases as they pass through a moistened filter.

- The outlet flow pressure will force the flow into the atmosphere, and clean air will exit the chamber through the top exhaust port. Separated dust at the bottom will be collected in a bottom chamber known as the collector. When the collector becomes full after a long period of time, it will be manually cleared. 


\section{c) Testing of the Model}

We employed "Pollution Checking Machines" to evaluate the device's actual performance, which included an exhaust gas analyzer, a smoke metre, and a combined PUC analyzer, which can quickly check the pollution level of various autos. Petrol is a Hydrocarbon (HC) that is composed of Hydrogen and Carbon. These two elements easily combine with oxygen. Water $(\mathrm{H} 2 \mathrm{O})$ is generated when hydrogen and oxygen combine. Carbon Monoxide (CO) and Carbon Dioxide (CO2) are generated when carbon reacts with oxygen.

If all of the gasoline in an engine is completely burned, the only components that exit out the tailpipe are $\mathrm{H} 2 \mathrm{O}$ and $\mathrm{CO} 2$. However, because perfect combustion cannot be achieved, some $\mathrm{CO}$ and $\mathrm{HC}$, as well as a third molecule, Nitrogen Oxide, are present in the exhaust (NOx). These are the three most dangerous pollutants that we are attempting to remove via the use of various pollution control systems such as Exhaust gas analyzers, Combined PUC Analyzers, and Smoke Meter fuel emission testing equipment.

An emission test cycle is a methodology included in an emission standard that allows for the repeatable and comparative measurement of exhaust emissions from various engines or vehicles. The particular conditions under which the engine or vehicle is run during the emission test are specified in test cycles. Various national and international governments and working parties have issued a variety of test cycles.

The Government of India established Bharat stage emission regulations to limit the production of air pollutants from internal combustion engine equipment, including motor vehicles. The Central Pollution Control Board, which reports to the Ministry of Environment, Forests, and Climate Change, establishes the standards and schedule for implementation.

We tested the device with the help of this pollution checking machine. We utilised a nozzle and a diffuser in that. As shown in the experimental setup portion, we used a diffuser before the inlet part of the device to slow down the speed of the incoming polluted air from the source and a nozzle after the outlet part of the device and just before the input segment of the pollution testing machine, which helps to increase the velocity of the NOx free air before entering the testing machine. In this manner, the testing gadget takes in the air to examine its quality and returns a result based on the quality of the air.

\section{Results AND DisCUSSION}

\section{A. Overall Performance}

We received our final system specification after successfully designing the device in CREO and testing it for velocity and pressure development in ANSYS Workbench. Then we coupled the filter with the gadget and chemically wetted it. As a result of PUC testing with the device, we were able to successfully reduce NOx existing in the vehicle's exhaust at a very low cost.

TABLE 3

TESTING RESULTS

\begin{tabular}{|c|c|c|c|c|}
\hline $\begin{array}{l}\text { Test } \\
\text { No }\end{array}$ & $\begin{array}{c}\text { Experiment } \\
\text { Setup }\end{array}$ & $\begin{array}{l}\text { Actual } \\
(\mathrm{g} / \mathrm{km}) \\
\text { (Direct } \\
\text { testing) }\end{array}$ & $\begin{array}{c}\text { Final }(\mathrm{g} / \mathrm{km}) \\
\text { (Testing with } \\
\text { Device) }\end{array}$ & $\begin{array}{c}\% \\
\text { Reduction }\end{array}$ \\
\hline 1 & $\begin{array}{l}\text { Only with inline } \\
\text { duct fan }\end{array}$ & 0.07 & 0.0539 & $23 \%$ \\
\hline 2 & $\begin{array}{l}\text { Only with } \\
\text { exhaust fan }\end{array}$ & 0.07 & 0.0574 & $18 \%$ \\
\hline 3 & $\begin{array}{l}\text { With both inline } \\
\text { duct fan and } \\
\text { exhaust fan }\end{array}$ & 0.07 & 0.497 & $29 \%$ \\
\hline
\end{tabular}

\section{B. Chemical Utilities}

As previously indicated, we used liquid urea as the chemical to perform the chemical reduction process and release NOx-free air into the atmosphere. For single testing of the system, we needed $150 \mathrm{cc}$ of liquid urea.

\section{Necessity of the Concept}

In today's globalised society, transportation around the globe has a significant impact on the quality of atmospheric air. So, in order to support life on Earth, it is critical that pure air for breathing is available in nature. We can only speculate on the lives of humans and 
animals in the future. We are quite used to utilising vehicles in our daily lives, and no one wants to worry about nature. As engineers, it is our job to work for our environment and make it livable for future generations. The primary goal of this initiative is to provide a solution to the problem of air pollution.

\section{Conclusions AND Future SCOPE}

\section{A. Conclusions}

Taking into account the different experimental projects being carried out around the world by large institutions and commercial firms, and merging the findings displayed by them with the same that has been put forward by this project. Few findings are certain, such as the fact that this system is more efficient and performs well at work. As a result, it has the potential to be widely employed in the future. Our technology is quite capable of reducing the amount of NOx present in the ambient air, the majority of which comes from vehicles. Some changes will be made to the model's structure in order to improve efficiency. The device's efficiency might vary depending on the power and rpm of the motor.

\section{B. Future Scope}

This method has a lot of potential for improvement. We are able to make certain changes to the design and specifications. We can make it more efficient this way. Those future horizons are

- Because a solar panel and sensors are employed, the device can be made automatic. In place of electricity, solar power or solar panels will be used.

- Additional filters and chemicals can be used to decrease additional contaminants. The model's performance will improve when the number of filters and chemicals is increased.

- To minimise the total weight of the device, aluminium sheets and fibres can be employed in place of steel sheets.
We can better control the system's operation if this system is employed in conjunction with computer control.

\section{REFERENCE}

[1] C. A. Miller, R. Hall, R. Stern, "NOx Control Technology Requirements Under the United States 1990 Clean Air Act Amendments Compare to Those in Selected Pacific Rim Countries", EPA 600/A-94-25.

[2] Nitrogen Oxides: Impacts on Public Health and the Environment, EPA 452/R-97-002.

[3] K. Chithambaramasari, N.V. Mahalakshmi, K. Jayachandran, "Application of SCR technique in NOx reduction of Diesel Engine Emission by Urea Injection Method", Canadian Journal on mechanical sciences \& Engineering, Vol.2 No.8, December 2011.

[4] S. Ghosh, Dr. S.N. Chaudhuri, D. Dutta, "Reduction of NOx emission by urea injection and marine ferromanganese nodule as SCR of diesel enginell", International Journal of Engineering Research \& Technology, Vol.2 issue 1, January 2013. [2]

[5] Ioannis Gekas, Par Gabrielsson, Keld Johansen, "UreaSCR catalyst system selection for fuel and PM optimized engines and a demonstration of a novel urea injection systemll", Society of Automotive Engineers, (2002-010289).

[6] M. Koebel, M. Elsener and M. Kleemann, Urea-SCR: a promising technique to reduce NOx emissions from automotive diesel enginesll, Elsevier catalysis today, Pg. 335-345, 2000.

[7] Yamamoto SS, Phalkey R, Malik AA., "A systematic review of air pollution as a risk factor for cardiovascular disease in South Asia: Limited evidence from India and Pakistan”, Int J Hyg Environ Health. 2014; 217:133-44.

[8] Zhang W, Qian CN, Zeng YX,. "Air pollution: A smoking gun for cancer", Chin J Cancer. 2014; 33:173-5.

[9] G. Oberdorster, R. Gelein, C. Johnston, P. Mercer, N. Corson, J. Finkelstein, "Relationships Between Respiratory Disease and Exposure to Air Pollution", International Life Sciences Institute, Washington DC, pp 216-229, 1998.

[10] Chen B, Kan H. "Air pollution and population health: A global challenge". Environ Health Prev Med. 2008; 13:94101. 
[11] Rumana HS, Sharma RC, Beniwal V, Sharma AK., "A retrospective approach to assess human health risks associated with growing air pollution in urbanized area of Thar Desert, Western Rajasthan, India”, J Environ Health Sci Eng. 2014; 12:23.
[12] M. Leenus Jesu Martin and V. Praveena, "A Review on Various After Treatment Techniques to Reduce NOx emissions in a CI Engine,” Journal of the Energy Institute, vol.91, October 2018, pp.704-720. 